\title{
Teoría General del Subempleo, el Desinterés y la Moneda
}

\section{Razón del título.}

El título ronda en lo cómico, pero quiere expresar algo muy serio. Sería necesario que un connotado neokeynesiano realizara una puesta al día de la obra del gran economista del siglo-XX, porque Keynes sigue teniendo razón: un fantasma recorre el mundo, el subempleo, y en el tercer mundo todavía peor... Como dijera Luis de Sebastián, la globalización muestra un frío "desinterés" frente a estos problemas. "Para el neoliberalismo, los fenómenos que desde una visión ética de la realidad socioeconómica llamamos "conflictos" (explotación, pobreza, desempleo, marginación, competencia desleal, fuga de capitales, quiebras bancarias, crahs de la bolsa, enfrentamientos regionales, etc.) son episodios necesarios y positivos de la lucha de los ejemplares más fuertes de la raza humana para conseguir mayor riqueza, mayor prosperidad, mayor bienestar para la humanidad en general, aunque no necesariamente para todos y cada uno de los miembros de esa raza. Pero eso no importa; la humanidad se considera mejorada con que algunos de sus miembros alcancen niveles nunca antes logrados de riqueza. Esto es un "desarrollo vicario", en el que los ricos ejercen la función de representar a toda la humanidad en el disfrute de los bienes materiales de la creación". (El neoliberalismo en cuestión. Sal Terrae, Bilbao, 1993; pp. 27-28)

Penetrando en las entrañas de la globalización los flujos multimillonarios de las bolsas de valores determinan el destino de la humanidad y la moneda se convierte en el álgebra del valor; la moneda determina el valor de toda la actividad humana. George Soros dice: "Los mercados financieros son inestables por naturaleza, y más todavía los mercados financieros internacionales... Los participantes en el mercado, si son racionales, reconocerán que más que descontando un futuro equilibrio están disparando contra un blanco en movimiento... La inestabilidad de los mercados financieros puede originar serias dislocaciones econó- 
micas y sociales... No se puede dejar que los mercados corrijan sus propios errores porque lo más probable es que su reacción sea excesiva y se comporten de forma indiscriminada"... Ralf Dahrendorf, del College Oxford, agrega: "Los bancos tienen una función fundamental en la economía global..., pero operan cada vez más en el ciberespacio de las operaciones financieras. Por supuesto, al hacerlo quieren agradar a sus clientes. Y estos clientes pueden volverse avaros. Para satisfacer estas demandas las instituciones financieras han desarrollado instrumentos cada vez más sofisticados y misteriosos. El mundo de los derivados y las opciones escapan a todo sentido común. Quienes se mueven en él utilizan una extraña mezcla de matemáticas avanzadas e intuición. Cada vez es menos fácil evaluar el riesgo que implican esas operaciones. En el proceso se corre un grave riesgo de que los bancos se extralimiten. Esto es lo que ocurrió en el Sudeste asiático... Las instituciones financieras están interrelacionadas y, si fracasan, afectan a la economía real $y$, por consiguiente, a las fuerzas coyunturales de todas partes... Un hombre como George Soros se ha servido de este hecho, pero también ha pedido normativas y regulaciones"...

El arzobispo de París, J. M. Lustiger, se expresa como un buen economista: "Se ha adoptado la psicología del financista. Si se busca el beneficio inmediato es seguro que se pone en peligro el largo plazo. La valoración financiera sustituye a los productos industriales y a los flujos destinados a la producción. La gestión financiera de las empresas puede llevar a preferir el beneficio más inmediato o de mayor riesgo, sin miras a la realidad circundante... La moneda es un símbolo abstracto, ella cuantifica toda la realidad, dándole un precio. La moneda es una especie de álgebra de la actividad humana, reducida a la medida de la unidad monetaria... La bolsa de valores funciona mejor que las Naciones Unidas. Los financieros anticipan la evolución de la humanidad. Pero, ¿es a ellos a quienes corresponde conducirla? Y ¿a beneficio de quién?”. (ECA, 1998; pp.898-904) De la econnomía basada en el trabajo a la ganancia esperada de la especulación. El título que ronda en lo cómico quiere expresar algo muy serio.

Así se explica que la globalización ha gestado una secuencia imparable de manifestantes y manifestaciones, sobre todo en el hemisferio Norte, donde y a donde escribió Keynes. Con fecha 19 de junio 2000, 60.000 trabajadores portugueses, españoles, franceses, italianos se manifiestan en Oporto (Portugal) para reclamar a los gobernantes europeos medidas concretas "para alcanzar el pleno empleo, la igualdad entre hombres y mujeres y el reconocimiento de los derechos socio-laborales en la revisión del Tratado de la Unión". Incluso la Europa de 300 millones cuenta con más de 16 millones de parados y cerca de 65 millones bajo el umbral de la pobreza. "Se habla mucho de pleno empleo, pero se hace muy poco. Además es necesario que se incorporen en el tratado de la UE (Unión Europea) los derechos laborales como el de la huelga, la negociación colectiva, la libre sindicalización o la directiva de las sociedades anónimas europeas, con la participación de los trabajadores". (García J. "Miles de trabajadores exigen en oporto el pleno empleo". El País; 20 junio) 
Como muestra E. Luttwak, en su obra: "Turbocapitalismo", en el mundo anglosajón pende una espada de Dámocles sobre la clase trabajadora: el "despido". Los sindicalistas hacen una acotación interesante: "Porque el modelo anglosajón que pretende imitar a Europa, no es el del pleno empleo, sino el del pleno subempleo". Esta es la razón del título, que en dosis mayor se aplica al Tercer Mundo, donde el subempleo tiene por nombre "sector informal". Con fecha 5 de julio, "sindicalistas del Grupo de los Siete, países más industrializados y Rusia (G-8) presentaron este miércoles una declaración que conmina a sus jefes de Estado y Gobierno a reconocer "la dimensión social de la globalización" y a frenar el deterioro de los derechos laborales en la cumbre que celebrarán del 21 al 23 de julio en Okinawa, al sur de Japón. El G-8 se reúne en un momento crítico... Las movilizaciones de Seattle fueron un aviso de que la gente duda de las promesas de la globalización, advirtió el secretario general de la Confederación Internacional de Sindicatos Libres (CISL), Bill Jordan". (La Prensa Gráfica, 6 julio 2000; pág. 38)

Queda por responder una interrogante: ¿por qué esta imparable secuencia de manifestaciones (Seattle-1999, Davos-2000, Bangkok-2000, Washintong-2000, Oporto-2000, ¿Okinawa-2000?...) estallan sobre todo en el hemisferio-Norte, cuando sobran las razones históricas para que fueran más bulliciosas en el hemisferio-Sur?- Tenemos que admitir que la respuesta se debe también a otra razón histórica; Europa cuenta con dos siglos de luchas y logros sindicales y vuelve a sentir hondas nostalgias por regímenes sociales más democráticos. "El Estado de bienestar, tan denotado por algunos, ha sido la seña de identidad de la construcción europea después de la guerra, los cimientos más sólidos sobre los que se ha ido forjando la Europa actual, esa mezcla equilibrada entre criterios económicos y justicia social. No debería ser necesario recordar cuál era la situación de la clase trabajadora al inicio de la revolución industrial, pero los amnésicos vocacionales deben tener la seguridad de que los sindicatos europeos no estamos dispuestos a tirar por la borda dos siglos de luchas sociales... Porque estamos convencidos de que la Europa del futuro debe responder no a los intereses financieros y mediáticos de una cada vez más poderosa elite, sino a las aspiraciones democráticas de la mayoría de los ciudadanos". (Méndez C. Y Fidalgo J.M.: "Por una Europa de pleno empleo y los derechos sociales". El País. 19 junio 2000)

Nosotros tenemos un notable déficit en esta historia de la sana organización sindical, hoy tronchada, pero tenemos un superávit en la tradicional supeditación y control de la clase trabajadora. Sería necesario que nuestras autoridades comprendan que los manifestantes y las manifestaciones, razonadas y racionalmente realizadas, son un signo de nuestros tiempos, abandonando el estribillo de que con ellas se busca la desestabilización política. La desestabilización y la ingobernabilidad están creando el mismo modelo de una globalización, que será recordada como "la era de las grandes desigualdades". En otras palabras, la secuencia de manifestantes y manifestaciones nos ayudan a realizar un racional 
proceso de autocrítica sobre los logros y aportes, así como de las consecuencias adversas de la globalización neoliberal, que pone en difícil situación a empresas del sector productivo, a amplios grupos de consumidores y por supuesto a la insegura clase laboral. Esta autocrítica, que emana desde el interior de la globalización, nos sirve para descubrir posibles vías alternativas de superación o de cohabitación con esta globalización imparable. Como todo modelo o sistema, la globalización no es, ni puede ser "el fin de la historia". Los manifestantes y las manifestaciones, razonadamente justificadas, así como los debates que se vienen realizando en recientes cumbres-reuniones mundiales nos ayudan a humanizar la historia. El primer ministro de Francia, Lionel Jospin ha dicho: "hay que analizar el capitalismo para reformarlo".

Al neoliberalismo le conviene recordar el ejemplo y la suerte corrida por aquél otro modelo, no sé si opuesto o similar, de los socialismos reales. Ellos quisieron planificar, desde una cúspide autoritaria, la política, la economía y hasta la misma vida espiritual, los valores y la conciencia de la población. Sus manifestantes y sus manifestaciones, las críticas e incluso la tardía autocrítica emanada desde la cumbre del sistema (Perestroika, 1987), colaboraron a desintegrar política y económicamente aquel sistema, mal llamado "modelo". La globalización neoliberal camina hacia el mismo destino porque pretende programar la política, la economía y la misma vida espiritual del mundo desde la cúspide de las megaempresas, desde la irracionalidad de la especulación de las bolsas de valores y desde los monopolios-multimedia, que destruyen valores tradicionales y humanos. Esta es también la tesis de E. Luttwak: "Los extremos se tocan, pues no deja de sorprender lo mucho que el nuevo turbocapitalismo tiene en común con la versión soviética del comunismo. Como en este último caso, también ofrece un sólo modelo y un sólo conjunto de normas para todos los países del mundo, pasando por alto todas las diferencias sociales, culturales y de temperamento. En cambio, el capitalismo controlado se gestionaba de formas muy diferentes en Estados Unidos, en Europa o en Japón, aun cuando en todos esos casos el objetivo era el establecimiento de ciertos límites a la competencia para, mediante el sacrificio de algunas de sus ventajas, dotar de estabilidad a las industrias y a la vida de los trabajadores". (Turbocapitalismo; pp. 49-50)

En Davos-1999 se dijo que la globalización era "imparable", pero en Seattle1999 los representantes de los países en desarrollo, con el apoyo de los manifestantes, frenaron el irrespeto de la globalización comercial. En Davos-2000 los representantes de la elite capitalista, Clinton y Tony Blair, recomendaron volver al diálogo y reanudar las conversaciones de la OMC. También las organizaciones sindicales defienden sus derechos, al mismo tiempo que crece la conciencia de que se hace necesario "gobernar la globalización". Todos estamos de acuerdo sobre los aportes positivos nacidos de la revolución tecnológica, al mismo tiempo que tenemos en cuenta las consecuencias negativas de lo que Schumpeter llamó la "destrucción creativa". Desde este aspecto se dijo en Bangkok que "la 
globalización hace difícil la globalización". También crece la conciencia general de que una de las partes integrantes de la globalización, los capitales especulativos de corto plazo desestabilizan las economías mundiales, sobre todo las de aquellos países que más los necesitan, pero que no cuentan con sólidas instituciones financieras. Igualmente, se elevan fuertes críticas contra los oligopoliosmultimedia, que buscan diluir valores y costumbres tradicionales, gestando un "homo economics" hecho para producir, ganar y consumir, sin otro "plus ultra" en su vida.

\section{Gobernar la globalización.}

Gobernar la globalización es la única forma de hacer posible la globalización. La pregunta-misterio es ¿quién gobierna la globalización?. Hace dos años transcribía la pregunta y la respuesta propia de la época: “¿Quién está a cargo de la economía global?- Nadie. Un mundo sin controles, sin reglas, es un mundo sin seguridad". (ECA, 1998; pp. 904-905) Desde entonces han llovido muchas inseguridades y se acumulan muchas razones para gobernar la globalización. Trato de hacerlo desde algunas de las caras de este prisma mundial.

\section{El control de los capitales especulativos.}

En este punto hay un consenso más generalizado desde la cumbre de Davos1999 hasta la reciente reunión de primavera del FMI, BM y G-7, tenida en Washington y que coincidió con el "viernes-negro" 14 de abril. En el artículo arriba citado se trasladan suficientes testimonios de autorizados economistas que solicitan el control de estos capitales especulativos, a comenzar por la recomendación del financista $\mathrm{G}$. Soros, quien lleva trabajando 40 años en las entrañas de este caballo de Troya. Cito solamente dos testimonios que emanan desde vertientes algo diferentes, expresados a inicios y finales de 1999.

El primero emana de los organizadores del foro de Davos-1999, en lo que podemos llamar su documento de antecedentes. La agenda del foro era: "La globalidad responsable". La crítica o autocrítica no se refiere sólo a los capitales especulativos: "La globalización debe adquirir un comportamiento social, que no tenga como contrapartida la miseria y exclusión de millones de seres humanos en el planeta... Esta crisis (1997...) es el resultado de una globalización que ha sido conducida de una manera irresponsable. Los problemas creados por la mundialización han desembocado en una crisis "sistémica". O se diseñan nuevas medidas para hacer frente a la crisis o estamos condenados a entrar en un período de caos endémico y sistemático". (C. Swadja) El principal animador de este foro, Klaus Achwad, "sostiene la necesidad de crear mecanismos globales e institucionales para lograr que la globalización se traduzca en fuente de bienestar para millones de personas que han sido condenadas a la miseria y desempleo... Miseria y desempleo, destrucción masiva de la riqueza financiera y mate- 
rial. Estados sometidos a la especulación, un capitalismo salvaje que erosiona las normas más elementales de la convivencia, son algunos de los rasgos que advertirían una globalización irresponsable"... (ECA, 1999; p. 465). Estos testimonios emanan de los organizadores del foro de Davos- 1999.

En noviembre-1999 el 21 Congreso de la Internacional Socialista (occidental), en su Declaración de París, se pronuncia a favor de la regulación de estos capitales especulativos de corto plazo: "Acabar con los flujos incontrolados de capitales, culpables, en opinión de los socialistas, de las continuas crisis financieras y colocarlos bajo el foro fiscalizador, constituye una respuesta a un fenómeno que amenaza con contaminar el sistema democrático. Sin transparencia y sin control, perdurando paraísos fiscales, será cada día más difícil luchar contra el blanqueo de capitales procedentes de prácticas corruptas enraizadas en algunos países y de flujos contaminados con origen en la criminalidad organizada internacionalmente. La Declaración de París “ afirma que la deriva de los capitales amenaza en toda regla a la seguridad de las naciones; el campo de la paz internacional, de la seguridad, tiene hoy una dimensión económica y financiera, que tenemos que enfrentar con valentía desde posiciones progresistas. Por eso es urgente asegurar una mayor transparencia del sistema financiero internacional, imponer reglas de prudencia a todas las instituciones financieras, incluso a los fondos de inversión especulativos y a las entidades extraterritoriales; abolir los paraísos fiscales; involucrar a las entidades prestamistas en la resolución de las crisis que contribuyen a formar". Recuerdo que esta Declaración de París viene firmada por los principales jefes de Estado o de Gobierno de Europa occidental; entre ellos Gerhard Schröder, que en Davos-1999 invocó a G. Soros, exigiendo una enérgica regulación de los flujos financieros especulativos. (ECA 2000; p. 64)

A partir de 1998 abunda la literatura recomendando el control de estos capitales especulativos, sea en cumbres mundiales (Bangkok-2000), sea de parte de analistas particulares o del mismo FMI (junio-2000), que recomiendan aplicar la "taxa-Tobin", como una de las medidas alternativas de control. (H.M.Wachtel: "Trois taxes globales pour maitriser la spéculatión". Le Monde, octubre 1998; pp.20-21. N. Chomsky: "Finances et silence". Le Monde, diciembre 1998; p. 21) Los acuerdos, a nivel nacional o internacional, versarán sobre las modalidades fiscales o monetarias del control, discusión surgida ya en el foro de Davos1999. En la reunión de ministros de finanzas del G-7 en Fukuoka, Japón, 8 de julio 2000, se emitió una declaración contra el lavado de capitales. El G-7 se propone tomar medidas concretas contra los países sospechosos de prácticas fraudulentas. En esta lista aparecen catorce países, entre ellos Rusia e Israel... L. Fabius ha dicho: "Se hace necesario pasar a una fase activa, iniciar un diálogo con los países y proponer medidas si ellos no se apegan a las prácticas legales". El G-7 invita a los bancos a ejercer "una seria vigilancia" sobre estos territorios. En concreto, "esto significa que los bancos franceses, ingleses o americanos deben examinar con cuidado las transacciones que llegan de los países miem- 
bros de esta lista negra y, eventualmente, transmitir sus dudas a las autoridades tutelares. Los organismos internacionales, a comenzar por el FMI, son invitados a participar en este proceso de vigilancia". ("Le G-7 séngage contre le blanchiment de capitaux". Le Monde, 8 juillet 2000)

Quince días más tarde, en la reunión de Okinawa, "El G-7 luchará contra el blanqueo de dinero para frenar el tráfico de drogas y armas": los líderes de los siete países más desarrollados resaltaron ayer, en un comunicado sobre la economía mundial, los peligros derivados del blanqueo de dinero y se comprometieron a desarrollar más la persecución a fin de contrarrestar el narcotráfico o el comercio ilegal de armamento. También se comprometieron en vigilar más las irregularidades de los llamados paraísos fiscales. "Estamos preparados para actuar juntos cuando así se requiera y sea apropiado a fin de aplicar medidas contra los países que más se distinguen en la práctica de esas operaciones fraudulentas"... (El País, 22 de julio de 2000)

En El Salvador, previendo algún reflujo de la crisis financiera, el BCR elevó de tres puntos los encajes legales en noviembre de 1998. El problema no es simplemente que nos pueden llegar o escapar cantidades ingentes del "hot-money"; basta con que los capitales golondrinas desestabilicen economías emergentes mayores (México, Brasil...) para que el efecto-dominó nos llegue vía comercio exterior. Los empresarios salvadoreños se han quejado, al parecer con plena razón, de algunas exportaciones provenientes del bloque sudasiático, con carácter de competencia desleal debido a las devaluaciones de aquellas monedas luego de su crisis financiera. La misma ralentización del comercio externo, consecuencia de la retirada de dichos capitales, traduce la crisis financiera en crisis económica. Con un descaro, que ronda en el cinismo, se dijo en Davos-2000 que los países emergentes sudasiáticos ya se han recuperado de la crisis de 1997. A estos representantes de la elite del capitalismo poco les importa el cúmulo de desempleo y pobreza, amén de las convulsiones sociales, aún permanentes en esos países.

Lo importante es recordar que el ingente mercado de los capitales especulativos es parte integrante de la actual globalización y que quienes profesan una fe impoluta en el "mercado" deben reflexionar mejor sobre todos los artículos de su credo. No existe un "mercado a la carta", al gusto de cada uno, y quienes se confiesan cofrades del mercado deben admitirlo o rechazarlo con todas las consecuencias reales. Lo menos que se puede pedir es escuchar a quienes recomiendan gobernar la globalización.

\section{Los estadígrafos de la globalización.}

No me refiero aquí a las estadísticas sobre los efectos mundiales de la globalización, que pueden leerse en los documentos de antecedentes de la cumbre mundial de Copenhague, 1995, (Realidad, No 42, 1994; pp.843...) o en el 
discurso de J. Wolfensohn, presidente del Banco Mundial, "La otra crisis". (ECA, 1998; pp.1003-1009) Se trata de un tema concreto y al mismo tiempo mundial: se globaliza el subemplèo. Hay dos problemas que corren líneas paralelas: el crecimiento con desempleo y la globalización del subempleo. Para los estadígrafos estos problemas pueden ser sólo estadísticas; pero cuando estos fenómenos se globalizan la sociedad entra en una grave "crisis de trabajo". Boutros Ghali dijo en Copenhague que esta crisis de trabajo se traduce en una crisis económica, crisis social, crisis moral y crisis de inseguridad; y todo ello deriva en una crisis de ingobernabilidad. El trabajo, que ha hecho la historia de la humanidad y de las personas, no puede reducirse a un cruce de curvas de oferta y demanda. Hay que analizar más detenidamente por qué fallan las expectativas de los demandantes laborales y las oportunidades de las empresas productoras. Entra en juego el proceso de "destrucción creativa", pero hay algo más que el desafío tecnológico.

Es cierto que la oferta de trabajo, llamada empresa, exige determinada formación y cualidades del sujeto demandante, pero el problema mundial es que, incluso con esa formación y cualidades los demandantes se ven excluidos o sometidos a un impreciso tiempo de espera. El regulador del mercado ordena aplicar una medida opaca y difusa: la "flexibilidad laboral", que frecuentemente es la "sumisión"laboral. Es lógico que, si el fenómeno se generaliza, los grupos laborales busquen una defensa y una explicación. Esto ha sucedido recientemente en Oporto (Portugal) y seguramente se repetirá en Okinawa. Frank Hinkelammert habla del "huracán de la globalización", del "jobless-growth" del continente latinoamericano, donde el trabajo "liberalizado" tiene que refugiarse en la supervivencia del sector informal.

Como en Estados Unidos y Europa se habla y disputan entre sí el objetivo del pleno empleo, uno de los analistas se pregunta: “¿cuánto empleo es pleno empleo?". El analista de la universidad de Alcalá, J. F. Jimeno, invita a revertir las estadísticas sobre la situación del empleo. De acuerdo a los métodos tradicionales habría en España una tasa de desempleo entre 15-18\%. (Sea dicho, entre paréntesis, que no debe ser muy realista nuestra tasa oficial de $7-8 \%$ de desempleo...) "Buscando un mejor indicador de la situación laboral" se está calculando directamente "la tasa de empleo", es decir el porcentaje de la población en edad de trabajar que ocupa un puesto de trabajo. Los resultados son iluminadores, y también lo serían para nosotros. "En España, a pesar de la intensa creación de empleos en los últimos cinco años, sólo alrededor del 55\% de la población de 16 a 64 años está ocupada. Además, el empleo está muy mal repartido: la tasa de empleo de las mujeres está alrededor del 40\%; la de los jóvenes de 16 a 24 años, alrededor del $30 \%$. Y lo que empieza a resultar insostenible, dado el proceso de envejecimiento de la población que se avecina, es que la tasa de empleo de la población de 55 a 64 años sea sólo del $50 \%$ para los varones y menos del $30 \%$ para las mujeres"... (EL País, 11 junio 2000) Por esta razón ellos hablan de "pleno subempleo", 
Dentro de ciertas variantes estas tasas de empleo fijo o completo son similares en otros países europeos y algunos autores afirman que algo así sucede en Estados Unidos pese a los 107 meses de crecimiento sostenido. Refiriéndose a la economía norteamericana E. Luttwak dice: "Ninguna estadística puede medir la "seguridad" del empleo, una apreciación en cualquier caso subjetiva. Igualmente subjetiva es la pretensión de los economistas más importantes en el sentido de que la sorprendentemente débil presión en favor de unos salarios más altos durante los años de expansión económica de los Estados Unidos, entre 19941998, se debió al temor de los empleados y de los sindicatos ante la posibilidad de que los puestos de trabajo se trasladasen a cualquier parte o simplemente desapareciesen si los salarios aumentaban. Lo que las estadísticas salariales sí muestran es que la inmensa mayoría de los empleados de cuello blanco menos calificados se han empobrecido en la economía norteamericana".

Luttwak prueba con estadísticas que el fantasma del "despido" sobrevuela tanto la tradicional manufactura como la industria de los servicios. Se mantienen las estadísticas del elevado empleo, ocultando el forzado descenso a trabajos menos remunerados. "Lo que ha convertido a las empresas norteamericanas en más eficientes desde los años ochenta es precisamente la reducción del número de gerentes superiores, incluida la total eliminación de los que tenían más de cincuenta años y no consiguieron llegar a la cima, pero cuyos salarios son bastante elevados y cuya edad provoca un aumento de los seguros médicos. Sobre todo es portándose mal con sus propios empleados más vulnerables como las empresas adelgazan... En este sentido, la vida de los norteamericanos en la era del turbocapitalismo es al mismo tiempo prometedora y peligrosa. Su riqueza material generalizada y sus oportunidades para alcanzarla van acompañadas de una soledad emocional generalizada. Demasiados cambios de residencia o de trabajo provocan la pérdida de las amistades menos sólidas, y los previsibles cambios por venir desaconsejan la profundización de las mismas. Así mismo, las vidas erráticas por lo general son incompatibles con la conservación de relaciones familiares intensas más allá de los límites del propio hogar"... (Turbocapitalismo; pp. 73-81) Algunos autores comentan que para el norteamericano medio su héroe imaginario sigue siendo el "vaquero del oeste", siempre en busca de nuevas tierras, sin apegarse a un lugar determinado. Así se explica el gran uso y demanda del correo electrónico para mantener la comunicación con sus familiares dispersos en el territorio nacional.

Descendiendo a nuestra pequeña tierra, con fecha 20 de junio, Francisco Molina se pregunta: "Distribución de la riqueza o crecimiento y libre mercado?". Aunque los datos se refieren al crecimiento y a la pobreza dejan traslucir el gran problema de desempleo-subempleo. "En El Salvador la estrategia de los gobiernos de ARENA, por lo menos en principio, ha sido dar al mercado el rol principal para el desarrollo del país. Los resultados obtenidos con este enfoque han sido mixtos. Si bien es cierto que la economía creció en promedio, de 1992 
a 1998, un 5,2\% en términos reales, en el año 1998 el $51 \%$ de la población total del país, esto es más de tres millones de mujeres, hombres y niños que todavía se encuentran por debajo de la pobreza. Es decir que durante ese periodo la pobreza se redujo únicamente en un $3 \%$. Indicando, contrapuesto al estudio del Banco Mundial, que en El Salvador, aun cuando la economía creció en forma robusta, la filtración de los logros del crecimiento económico hacia los pobres fue lenta. Esta comprobación debería haber llevado a nuestro gobierno a revisar algunos de los supuestos en que se fundamenta la estrategia de desarrollo del país y a comprender que el funcionamiento del mercado no puede, por sí sólo, alcanzar los esperados logros de bienestar social para las mayorías". (El Financiero. La Prensa Gráfica, 20 junio 2000; p.46).

Estando totalmente de acuerdo con F. Molina, es claro que bajo las estadísticas de la pobreza se trasluce la situación del grave desempleo-subempleo. R. Rivera Campos concluye su estudio sobre la economía salvadoreña de fin siglo con una reflexión similar a la de F. Molina. "Pero también es necesario convertir ese crecimiento en reducción de la pobreza, y para eso se necesita un acuerdo de largo plazo que establezca compromisos de invertir en los pobres, de establecer las políticas públicas para enfrentar sostenidamente las carencias sociales que se han señalado en este y otros estudios". (p. 246-247) Un año antes R. Rivera Campos había dirigido al grupo de investigadores que, entre otros temas, analizan la situación del empleo-subempleo en El Salvador, 1992-1997. ("Estado de la nación en desarrollo humano"; pp. 37...)

La realidad del desempleo y del subempleo supera las estadísticas oficiales, por lo que se hace necesario investigar directamente el empleo fijo o completo, de acuerdo al ejemplo antes comentado: ¿cuánto empleo es pleno empleo?. Algunos miembros del saliente equipo de gobierno veían, mayo-junio 1999, como un éxito la contracción de la inflación hacia el límite cero, que terminó siendo negativa. Se atribuía este éxito a las políticas antiinflacionarias del BCR, que nos situaban a niveles privilegiados e inferiores a la inflación internacional. Si una inflación elevada, caso de los años $1985 \ldots$.., es el peor de los impuestos indirectos, una inflación cero o negativa necesita una verdadera explicación. En el análisis de coyuntura del primer semestre de 1999 nuestro Departamento de Economía transcribía una reflexión de la revista The Economist: "La deflación puede ser positiva o negativa, dependiendo de sí esto lleva a una depresión, o si en realidad es el resultado de aumentos en la productividad". (ECA, 1999; p. 725...) El segundo término explicaba la situación, por ejemplo, de los 107 meses de crecimiento sostenido con baja inflación de la economía norteamericana, mientras que nuestra deflación se explicaba simplemente por lo que los diarios de fin de año titularon: "1999 el año perdido". El declive venía desde 1996 y la tasa cero de inflación se explica por la pérdida del poder real de compra de la población desempleada y subempleada, cuyos salarios mínimos habían perdido un $20 \%$ de su poder adquisitivo de 1988 a 1998. Las políticas antiinflacionarias, 
traducidas en elevadas tasas de interés real, alimentaron —en estas circunstancias- la recesión de la inversión, del empleo, de los ingresos y de la misma deflación regresiva. Volvemos a la teoría general del subempleo.

\section{5. ¿Quién controla el empleo?}

Trato de esquematizar este interrogante a nivel de países desarrollados y en desarrollo. Arthur Schlesinger, asesor del presidente J. F. Kennnedy, se preguntaba hace tres años: “ $¿$ Tiene futuro la democracia?". Analiza los efectos de la globalización desde lo que él llama la ley de la aceleración. "La ley de la aceleración nos precipita ahora en una nueva edad. El paso de una economía basada en la industria a otra basada en el ordenador es más traumática que el paso de nuestros bisabuelos desde una economía basada en la agricultura a otra basada en la industria. La revolución industrial se extendió sobre generaciones y dio tiempo a reajustes humanos e institucionales. La revolución informática es mucho más rápida, más concentrada y más drástica en su impacto. Mientras la revolución industrial creó más puestos de trabajo de los que destruyó, la revolución informática amenaza con destruir más puestos de los que crea. Amenaza también con levantar nuevas y rígidas barreras de clase, especialmente entre los instruidos y no instruidos. La desigualdad económica ha aumentado ya en los Estados Unidos hasta el punto de que son mayores las disparidades en el igualitario Estados Unidos que en las sociedades clasistas de Europa. Felix Rohatyn... habla de las tremendas transferencias de riqueza desde los trabajadores de baja capacitación y clase media a los propietarios de los bienes de capital y a la nueva aristocracia tecnológica".

E. Luttwak llega a la misma conclusión y resume el "raciocinio" de quienes ven normal la desigualdad. "Otra consecuencia inesperada del turbocapitalismo es el incremento exponencial de los ingresos de la gente que más gana... Mucha gente siente que la desigualdad es algo malo, pero en la concepción económica anglosajona - la única existente hoy día- esto no es un problema, sino parte de la solución. La competencia, que debe ser una cosa buena porque mueve la maquinaria de la prosperidad, a su vez recibe el impulso del incentivo de una mayor recompensa para los competidores con más éxito, y eso acarrea automáticamente más desigualdad, siendo otras cosas - incluidos los impuestos iguales. La mayor es la diferencia de ingresos, la más fuerte el incentivo, la más intensa la competencia, la mayor la prosperidad resultante. Así pues resistirse a la desigualdad de ganancias en nombre de la igualdad supone resistirse a la propia prosperidad. Reducir los impuestos de los que más ganan es el camino más rápido para incrementar el incentivo de la competencia, con el consiguiente incremento de la prosperidad. Que aumente demasiado la desigualdad es inevitable, y hasta el día de hoy no hay nadie que se lamente por eso a menos que uno también quisiera lamentarse por el aumento de la prosperidad. Estos pocos argumentos proporcionaron toda la base intelectual de lo que se conoce como 
thatcherismo en el Reino Unido. No fue necesario ponerle un nombre en Estados Unidos, donde la "economía de la oferta" de Ronald Reagan incluyó algunos pasos más allá con la promesa de una mayor prosperidad, un mayor gasto gubernamental y un presupuesto equilibrado por medio de la reducción de los impuestos para provocar que los ricos fueran más ricos, cuyos ingresos imponibles al final aumentarían tanto que unos impuestos más bajos podrían proporcionar una recaudación mayor, una realidad a partir de 1998". (Turbocapitalismo; p. 79-80)

Antes de referimos a nuestro continente agregó otro testimonio de Alain Tourraine, director del Instituto de Estudios Superiores de París. "El descontento, la inquietud y la protesta se hacen oír de nuevo: ¿Cómo podía ser de otro modo cuando la parte del producto nacional que va a los asalariados ha disminuido masivamente - alrededor de un 10\% - tanto en Alemania como en Francia, y cuando el salario real de los trabajadores menos calificados ha disminuido en los Estados Unidos, aunque ese país esté experimentando éxitos económicos sin precedentes"... (ECA, 1998; pp. 987-898). Esto explica la serie imparable de manifestaciones que desde 1999 se siguen repitiendo al interior de los mismos países desarrollados, calificativo que va más allá de "industrializados", en razón de la "nueva economía".

Descendiendo al continente latinoamericano F. Hinkelammert habla del "Huracán de la globalización". El esceñario es el gran océano en cuyo interior las multinacionales se ubican, a modo de archipiélago. Los países del primer mundo dependen de un crecimiento intensivo, altamente tecnificado, que ha logrado los límites técnicos posibles. "Aunque este archipiélago de inversiones intensivas en alta tecnología está ubicado sobre todo en el Norte, esta relación no puede entenderse como una relación Norte-Sur, sino como una relación de exclusión. Hoy día se habla de un tercer mundo en el primer mundo y de un primer mundo en el tercer mundo". A nosotros nos afecta el segundo término de esta exclusión, dada la libertad de flujos de mercancías y capitales y la ausencia de intervenciones estatales a estos flujos. Incluso la teoría ordena que los Estados deben facilitar estos flujos de mercancías y capitales, y fomentarlos son subvenciones.

En este escenario, las inversiones productivas nacionales deberían ser competitivas para poder realizarse. Esto exigiría una protección y fomento del Estado, tal como lo hicieron los tigres o dragones del bloque sudasiático. Dado que la teoría ordena la apertura, los enclaves de este archipiélago conservan su dinámica hacia dentro y una exclusión hacia fuera. Las inversiones productivas no se realizan; se genera la tendencia hacia la estancación dinámica (jobless-growth), el bloqueo al crecimiento del capital productivo. Al ser bloqueados por la competencia, los capitales disponibles tienden a ser invertidos especulativamente. Los capitales disponibles, buscando su rentabilidad, se asocian a la cacería de las privatizaciones de los servicios públicos, porque ya no encuentran otros nichos productivos donde mejorar su rentabilidad. Al mismo tiempo, la fuerza de 
trabajo "liberada" tiende a refugiarse en el sector informal, en situación de precaria subsistencia. El interrogante es dónde irán a buscar su rentabilidad los capitales disponibles una vez se privatice todo lo privatizable.

Hinkelammert agrega que en apoyo de esta política de exclusión se utiliza la teoría de las ventajas competitivas, de acuerdo a la cual se beneficiarían todos los países participantes del comercio. La tesis es clara: "no es posible que comprar barato sea la manera más cara de comprar". Sin embargo, la situación es diferente en este escenario de exclusión. "En esta situación, el libre comercio destruye mayores ingresos de los que se generan de la compra más barata. Efectivamente, se compra más barato, pero esta compra lleva a la destrucción de la producción que había permitido determinados ingresos. Al destruir esta producción, sin sustituirla por nueva y más eficiente, se pierde este ingreso sin ninguna contrapartida igual o mayor". Hinkelammert llega a formular algunas conclusiones que merecen toda reflexión. "Si la exclusión de la población resulta inevitable dentro de cualquier política de crecimiento, hace falta enfrentar la misma economía de crecimiento, si se quiere una solución a este problema. Dado el estancamiento dinámico no se puede tener la competitividad como criterio central del desarrollo económico. La competitividad resulta en que siempre hay quien gana y quien pierde. Para quien pierde esto equivale a una condena a muerte... Por esta razón el perdedor de la competencia tiene el derecho a protegerse $y$ es bien racional que lo haga... Por tanto no debe aceptar el juicio del mercado. Producciones no competitivas son económicamente racionales siempre y cuando las ventajas de la competencia -es decir, el acceso a bienes más baratos- sean superadas por las pérdidas de ingresos por medio de la eliminación de las producciones no competitivas". ("El huracán de la globalización". Economía Informa; marzo 1997; pp. 14-16)

Luego de escuchar los breves testimonios de A. Schelesinger y A. Tourraine, referidos a economías desarrolladas, y el escenario presentado por $\mathrm{F}$. Hinkelammert, queda pendiente una seria reflexión: "Si la exclusión de la población resulta inevitable dentro de cualquier política de crecimiento, hace falta enfrentar la misma economía de crecimiento, si se quiere una solución a este problema..." Por supuesto que Hinkelammert no pretende defender la indolencia de muchos sectores empresariales que, pese a las exenciones y subvenciones estatales, en poco o en nada se esforzaron por mejorar su calidad técnica competitiva, con daño para los consumidores nacionales. Por ello cita a Ander Gunder Frank: "América Latina es el continente de la "lumpem-burguesía", que sigue exportando mayoritariamente productos agrícolas y minería, sin mayor exportación industrial. Estas afirmaciones de Hinkelammert van a cobrar resonancia con ocasión de la firma del TLC con México. La Prensa Gráfica, en su sección de El Financiero, presenta "El clamor de la pequeña empresa. Sector no quiere ser excluido de la globalización". Los pequeños y medianos empresarios señalan diez problemas que generan su baja competitivad, solicitando ayudā́ y respues- 
tas para no ser arrollados por esta apertura comercial. (El Financiero, 4 de julio 2000; pp. 10 b)

Parecería que estamos volviendo a aquellas discusiones de inicios de los 90', cuando estaba de moda la teoría del rebalse. Primero, aumentemos la tarta y luego vendrá la distribución. ("Piezas para un modelo económico". Realidad Económico-Social, 1992; pp. 501-523) La historia ha sido la del refrán popular: el que parte y reparte se queda con la mejor parte. Eran los años en que la CEPAL nos recomendaba "Un enfoque integrador: equidad y transformación productiva", 1992; "Imágenes sociales de la modernización y la transformación tecnológica", 1995. Por desgracia, al terminar la década vemos que no se logró ni la transformación productiva ni la equidad entre nosotros. La teoría del rebalse tampoco juega ni ha jugado a nivel mundial; algún humorista pudiera inventarse la "teoría del embalse", todo para dentro, que es más cierta.

En el seminario antes citado, "El neoliberalismo en cuestión", Luis de Sebastián escribía desde Europa: "Esto nos lleva a insistir en la redistribución de los frutos del trabajo, del capital y de la tierra ( y otros recursos naturales) de una manera más coherente con el destino universal de los bienes. La redistribución, que los neoliberales relegan al final del proceso de crecimiento, convirtiéndola en una redistribución "escatológica", o sea, al final de los tiempos, tiene que ser el grito de movilización contra el neoliberalismo. El efecto rebalse, es decir, que llegue a los niveles inferiores de ingresos lo que sobra en los superiores, no es aceptable éticamente, ni funciona adecuadamente. Ya los clásicos de la Economía Política de los siglos XVIII y XIX ... comprendieron y explicaron en páginas lúcidas... que el proceso de distribución del producto nacional es un proceso conflictivo en el que priman las relaciones de fuerza de los distintos grupos que se disputan el pastel; que la distribución del producto dejada al mercado es desigual y normalmente injusta; y que la sociedad tiene que intervenir de alguna manera para moderar estos conflictos y redistribuir equitativamente lo que las relaciones de fuerza distribuyen con poca equidad.

Ahora tendríamos que ver paso a paso cómo las propuestas neoliberales ignoran los dos supuestos mencionados y, en consecuencia, las exigencias de la justicia y la equidad; cómo se tendrían que formular las políticas económicas y sociales para tenerlas en cuenta; cómo se tiene que compatibilizar la redistribución con la eficiencia en la producción —el tema preferido de los neoliberales-, pero, en concreto, en una sociedad avanzada pero en crisis, como la nuestra, y en nuestro entorno internacional. Aquí hay un conflicto, el conflicto entre la eficiencia y la distribución, que no se puede ignorar en favor de ninguno de los dos términos con exclusión del otro. Esto teóricamente está muy estudiado, pero parece que resulta muy difícil realizarlo en la práctica política. Este debería ser, a mi manera de ver, la tarea del seminario". (Ibídem; p. 28-29) 
Una frase que se ha repetido en reuniones y cumbres mundiales define a la globalización como la era de las grandes desigualdades. Al mismo tiempo que se reconocen los aportes positivos de la revolución tecnológica, también hay que tomar en cuenta que esta revolución tecnológica es un proceso de "destrucción creativa" (Schumpeter). En el análisis de la globalización hay que integrar ambos resultados. FUSADES presentó su programa económico con el título: "Crecimiento con participación”..., 1999. El título nos regresa a la reflexión de Hinkelammert: "Si la exclusión de la población resulta inevitable dentro de cualquier política de crecimiento, hace falta enfrentar la misma economía de crecimiento". Podemos analizar esta reflexión desde otra cara de la teoría del crecimiento.

\section{Las ventajas competitivas ¿son competitivas?}

Un regalo best-seller sería la obra de $M$. E. Porter: "La ventaja competitiva de las naciones". En sus mil páginas encontramos teoría y ejemplos aplicados de la teoría. Por otra parte, J. Stiglitz, hasta hace poco economista jefe del Banco Mundial, ha dicho que la globalización no ha beneficiado a los países pobres y que la teoría del libre comercio es "un fraude intelectual". (El País, 20 diciembre 1999 . Le Monde, 31 de enero 2000). A finales de 1999 y en lo que llevamos del 2000 se han confrontado, en forma enconada, los principios de la teoría con la historia real del comercio internacional. Baste recordar las confrontaciones entre naciones, sumadas a la presencia de manifestantes, en las cumbres de la OMC en Seattle, de las Naciones Unidas (UNCTAD), Bangkok, de la Unión Europea y Africa en El Cairo, del grupo de los 77 (G-77) en la Habana... No es posible ir más allá de unas simples pinceladas.

En la cumbre de la OMC en Seattle, por primera vez, los representantes de los países pobres se niegan a firmar un documento final, de acuerdo a la tradición, cuando ni siquiera habían sido consultados sobre los temas de agenda, ni habían participado en la preparación de los borradores. Los más de 40.000 manifestantes acusan a la OMC de ser "la Babilonia del segundo milenio, una especie de siniestra organización de rostro anónimo, convertida en el motor de una globalización que sólo favorece a las grandes empresas multinacionales... No hay transparencia alguna en todo el proceso y americanos y europeos juegan con nosotros con la política del palo y la zanahoria. No sabemos qué decisiones se van a tomar y una vez más se nos pedirá subscribir un texto que ni tendremos tiempo de leer..."

Con gran disgusto de los países en desarrollo vuelve a surgir el tema de las grandes subvenciones europeas y norteamericanas a la producción y exportación agrícola: 40,5 millones de euros y 22 mil millones de dólares respectivamente. Para la Unión Europea la "agricultura" no es una rama económica cualquiera, sino que goza de una "multifuncionalidad" con profundas implicaciones socia- 
les, culturales y ambientales. (ECA, 2000: pp. 60-65...) Los agricultores de ultramar no pertenecen a esta estirpe "multifuncional". Se logró contener, de momento, el libre comercio de los alimentos transgénicos, con que Estados Unidos quería aliviar el hambre del mundo, porque no está probado científicamente que no sean dañinos para la salud. Pero sí se logró mantener el arancel cero, hasta 2001, para el servicio del Internet dominado por Estados Unidos. Uno de los puntos que generó la ironía de los europeos y la cólera de los países en desarrollo fue la amenaza de aplicar restricciones comerciales a países que no respeten los derechos y normas laborales o que irrespeten el medio ambiente. La ironía y la cólera se explican porque los Estados Unidos no han firmado la mayoría de acuerdos de la OIT y muchas de sus internacionales utilizan mano de obra infantil e irrespetan el medio ambiente en ultramar. Por primera vez en Seattle se puso un freno a la globalización "imparable" y se lo pusieron los países pobres. En la conferencia de las Naciones Unidas (UNCTAD) sobre comercio y desarrollo, tenida en Bangkok, Tailandia, febrero 2000, los países en desarrollo solicitan, como objetivo mínimo, que los países ricos ofrezcan una entrada libre, sin cuotas ni tasas, a los productos (alimentos, textiles) de los 48 países más pobres, cuyas exportaciones representan sólo el $0,5 \%$ del comercio internacional. Aún en este caso se prefirió una fórmula vaga y limitante, haciendo referencia a "lo esencial de los productos" exportados y no a todos. En Bangkok aflora, una vez más, la doble moral o cinismo de los países ricos que anuncian un reducido perdón o alivio de la deuda externa y al mismo tiempo cierran sus fronteras a las exportaciones de los más endeudados. Volvemos a recordar a J. Stiglitz y su tesis del "fraude intelectual".

Con otras palabras, el presidente saliente del FMI, M. Camdessus, lo afirmó en su discurso de despedida en Bangkok. Luego de asegurar que la globalización "ofrece la mejor vía para mejorar la condición humana en todo el mundo", Camdessus se pregunta: "¿por qué tanta ansiedad y por qué tantos la rechazan como un símbolo de las nuevas tendencias económicas?- La respuesta es que aún no se ha demostrado que la globalización se preocupe lo suficiente por el problema más grave de esta era, la pobreza, o que sea capaz de resolverlo. La creciente brecha entre los ricos y los pobres son moralmente inadmisibles, económicamente ineficientes $y$, desde el punto de vista social, potencialmente explosivos. Hoy es evidente que no basta aumentar el tamaño de la torta; la forma en que se reparte es esencial para la dinámica del desarrollo. Si no ofrecemos esperanza a los pobres, la confrontación, la violencia y las conmociones civiles terminarán socavando la estructura de la sociedad... La respuesta es un multilateralismo más vigoroso. Pero la comunidad internacional da con una mano y quita con la otra. Los gobiernos han adoptado la decisión transcendental de reducir aproximadamente a la mitad la deuda de 35 ó 40 países pobres muy endeudados a través de la iniciativa para los PPME (países pobręs más endeudados). Pero estos mismos gobiernos no han podido —en el marco de la OMC- 
iniciar una nueva ronda de negociaciones o ni siquiera eliminar las barreras que se imponen a las exportaciones de los países más pobres, especialmente los PPME..." (FMI-Boletín, 28 febrero 2000; pp. 50-52)

R. Ricupero, Secretario General de la UNCTAD, agrega nuevas dificultades a la pesada losa de la deuda externa. Terminada la guerra fría se reducen sensiblemente las ayudas oficiales de los gobiernos, relegando esta función al libre mercado de capitales, siendo estos capitales un sustituto imperfecto de las ayudas oficiales. "En anteriores décadas la ayuda oficial de desarrollo era el termómetro de la solidaridad internacional y podía encauzarse a los sectores más pobres de la sociedad. En las presentes décadas estas ayudas han disminuido en términos reales e incluso nominales y tampoco se destinan en proporción mayor a los países pobres". Con fecha 15 de julio 2000 El País comenta que, en razón de la ayuda de reconstrucción de los Balcanes, "La UE disminuye su ayuda a la cooperación para Latinoamérica". Sobre el gravamen de la deuda externa se agrega la sensible disminución de la demanda de los productos básicos en el comercio internacional, mientras que las exportaciones tradicionales se ven sometidas a ciclos alternativos que desorientan y desaniman su producción. La diversificación de la producción y de las exportaciones requiere tiempo, inversión y nuevas tecnologías, que están al alcance de pocas economías. Sólo los gobiernos que disponen de medios necesarios pueden dedicar fondos a la investigación y promoción de nuevas tecnologías y de la competitividad de productos transables.

Las nuevas tecnologías son aseguradas por "Derechos de Propiedad Intelectual"; derechos honerosos para los países pobres e imposibles para los más pobres. "En términos más generales, los miembros de la Organización Mundial del Comercio, cuyas empresas están a la cabeza de la tecnología de punta, aprovechan rápidamente el sistema para "asegurarse" su ventaja competitiva, velando porque los mercados permanezcan abiertos a los productos fabricados con esas tecnologías... Si el conocimiento tecnológico es la clave del desarrollo, los gobiernos deberían formular políticas de fomento de estos conocimientos y calificaciones técnicas. Sin embargo, muchos países en desarrollo son incapaces de afrontar este desafío y poder cumplir en forma significativa con las normas exigidas en el marco de la OMC"... (R.Ricupero. Realidad 1999; pp. 664-668)

En la reunión de Bangkok, como en la subsiguiente reunión de El Cairo, abril 2000 , los países en desarrollo vienen solicitando que, como objetivo mínimo, jueguen las ventajas comparativas en los rubros de productos - alimentos básicos y textiles- donde países en desarrollo gozan de una real ventaja competitiva. Una vez más, las subvenciones y protecciones a los productos agrícolas del Norte, amén de los contingentes y barreras no arancelarias a los textiles y, a veces al calzado, desvanecen dichas ventajas comparativas. Al mismo tiempo "la Academia de Ciencias de EEUU respalda el uso de semillas transgénicas". 
En Seattle se había rechazado esta propuesta norteamericana, por cuanto no está científicamente demostrado que estén exentas de futuros daños a la salud y porque podrían inundar los mercados de países en desarrollo, acabando con los cultivos naturales y tradicionales. Esta propuesta ha sido recibida ahora con escepticismo por otros sectores más críticos. La Asociación de Científicos Preocupados de Washington asegura: "Hay pocas razones para creer que la ingeniería genética será mejor que otras ingenierías. En la mayoría de los casos la ingeniería se aplica a los cultivos que son más importantes para los países desarrollados, no a las cosechas de las que dependen los países pobres". En los mismos EEUU se percibe "un creciente malestar ante la comida genéticamente alterada". (El País, 12 julio 2000) En la reunión de Okinawa continúan divididos Europa y los EEUU por el problema de los alimentos transgénicos. La Unión Europea, aunque' reconoce las ventajas de estos alimentos, considera necesarias restricciones a su producción por los riesgos que comportan. En cambio Estados Unidos apuesta por la liberalización completa, a menos que haya pruebas científicas en contra". (El País, 23 de julio de 2000).

Dentro del tema de las ventajas competitivas conviene hacer una breve referencia a la actual reunión del G-7 y G-8 (Rusia) en Okinawa. Se esperaban mayores avances y promesas concretas de ayudas a los países en desarrollo. Pero "la carta de Okinawa" ha generado gran decepción. Los representantes del G-7 afirman que la economía mundial da signos de crecimiento sostenido en EEUU, Europa e incluso Japón, país anfitrión, también muestra indicios de recuperación, aunque debe animar su demanda deprimida. Todo irá bien a menos que no se disparen los precios del petróleo y que los capitales fraudulentos generen nuevas crisis financieras. El desafío pendiente es aliviar el problema de la pobreza y la reducción de la deuda extema de los países más pobres. Quienes parecen haber hablado con mayor preocupación han sido Jacques Chirac de Francia, y Yhosiro Mori de Japón. Chirac dijo: "Yo desearía que el siglo-XXI pudiera ser el siglo de la erradicación de la pobreza, así como el siglo-XX ha sido el de las independencias. Para conseguirlo es necesario construir un entomo económico abierto y estable, proseguir la ayuda al desarrollo y aligerar el peso de la deuda". Y. Mori ha prometido una ayuda de $\$ 15.000$ millones para que los países más pobres adquieran los conocimientos técnicos de la informática-Internet, y se reduzca la brecha creciente de estas innovaciones tecnológicas...("Pauvreté dans le monde"... Le Monde, 21 juillet 2000)

Una vez más Okinawa ha abundado en palabras huecas sin aterrizaje a compromisos concretos. Queda en el vacío la reducción de la deuda externa, porque sólo se han aliviado unos $\$ 15.000$ millones de los $\$ 100.000$ millones prometidos en Colonia el pasado año. Se siguen imponiendo excesivas restricciones del FMI a los casi 50 países beneficiarios de estas condonaciones. El monto de la deuda pendiente hace imposible que estos países se integren en la nueva economía mundial. Tampoco se ha firmado un compromiso por realizar en el presente 
año la prometida reunión de la Organización Mundial del Comercio (OMC), anunciada en Davos-2000. Permanecen las normas y los poderes asimétricos tradicionales en esta institución. La novedad de Okinawa ha sido resaltar la existencia de una "brecha digital", que ampliará la "brecha económica" NorteSur, en el momento en que la economía "mundial" da signos de mayor fortaleza. En este escenario el premier japonés Y. Mori anuncia su ayuda de $\$ 15.000$ millones para que los países pobres puedan adquirir esta tecnología informática y así obtener ventajas competitivas en la abierta economía mundial.

Estos silencios y esta promesa han recibido fuertes críticas de los representantes de los países del tercer mundo. Un representante africano ha dicho: "No podemos comer computadoras. La gente está muriendo". ("G-8 ofrece computadoras e Internet a países pobres". El Diario de Hoy, 23 de julio 2000; p. 11) De hecho, "La Carta de Okinawa defiende la apertura de mercados que facilite la propagación de la tecnología de la información, la protección de los derechos de propiedad intelectual, la proliferación del comercio electrónico sin eliminar cargas impositivas, la protección de datos y la defensa de una mayor coordinación en la lucha contra el delito cibernético"... La ONG Jubileo-2000, la más activa en esta cumbre, calificó de "indignante y cínica" la actitud japonesa (que quiere vender su producción informática), así como la de todos los países ricos. "El G-7 en vez de avanzar ha retrocedido en todas sus promesas"; olvidando los problemas de la pobreza y de la deuda externa. Lo que se ha pretendido en Okinawa es regular, a favor de los grandes, el comercio electrónico y el acceso a la revolución del Internet, También Kofi Annan confesó estar decepcionado por los escasos resultados de Okinawa.

Cerrando la cumbre el G-8 emite un comunicado con un preámbulo y tres capítulos sobre el siglo-XXI, titulados: "Mayor prosperidad, Tranquilidad de conciencia y Mayor estabilidad mundial". No sabemos a qué porción del sigloXXI se refieren estos capítulos, porque en el preámbulo aparecen dos afirmaciones "de suma cero": "en la última parte del siglo-XX la economía mundial ha alcanzado niveles de prosperidad sin precedentes", pero se agrega: "en muchas partes del mundo la pobreza y la injusticia minan la dignidad y los conflictos producen sufrimientos humanos". El comunicado integra las catorce conclusiones de Okinawa... Promesas y con-promesas, la mayoría de las cuales buscan la prosperidad, tranquilidad y estabilidad del primer mundo. ("La cumbre del G-8 augura "prosperidad" y se compromete a ayudar al Tercer Mundo". El País, 24 de julio de 2000). El enviado especial de Le Monde dice más con menos palabras: Las ONG denuncian "el paso atrás" (Les ONG dénoncent un "pas en arriére". Le Monde, 24 juillet).

Aparece una vez más la teoría del "desinterés" por los mayores problemas del tercer mundo. Clinton llegó tarde y se regresará antes para lograr un éxito en las negociaciones palestino-israelitas. A los países grandes les interesa más el 
arreglo de la deuda externa de Rusia, no condonable sino negociable en el Club de París (Club de los grandes países) y que ese país no se preste, con sus nuevos "zares" al descarado blanqueo de dinero. A todos los G-7 les interesa más las regulaciones de la nueva economía del Internet, que la revisión y diálogo de la OMC. El tema de la pobreza, de las tres enfermedades (sida, malaria, tuberculosis) y el "fardo"de la deuda externa quedan como encomiendas de otras comisiones. ("El G-7 exige condiciones para acelerar el perdón de la deuda a los países más pobres". El País, 22 julio 2000.

"El G-8 mundializa la revolución digital". El País, 23 julio 2000)

Al redactar estas líneas nuestro ministro de Economía, Ing. M. Lacayo, trata de responder a una serie de interrogantes que se levantan a raíz de la firma del TLC con México: “ México nos va a invadir con sus productos. El tamaño de la economía mexicana es mucho mayor que la salvadoreña. México no eliminará las trabas al comercio. No existen mecanismos de defensa para los pequeños empresarios. Los exportadores continuarán teniendo problemas de transporte cuando ingresen al territorio mexicano. México cuenta con mejores recursos, lo que le da una mayor ventaja". (Mitos y realidades del TLC con México. El Mundo, 23 junio 2000; p.12) Aunque el señor ministro trate de despejar estos "mitos", hay razones suficientes para tomarlos muy en cuenta a la luz de los artículos del tratado. El largo proceso de negociación del TLC con México y del ICC con EEUU son una prueba del difícil camino a desbrozar en el comercio internacional, y es normal que dejen flotando estos interrogantes. No sólo la Asamblea Legislativa, sino los sectores más afectados tendrán que hacer análisis y propuestas antes de la ratificación del tratado. Y después de la ratificación vendrán las experiencias reales. Uno de los aspectos positivos de la firma de estos tratados es que se toma conciencia de avanzar hacia una verdadera integración centroamericana, primer peldaño para transitar a la globalización comercial.

\section{El Estado en la era de la globalización.}

Luego de la crisis de 1930 se dijo que el "mercado es el problema". Llegados a 1970, y sobre todo luego de 1989 , se da vuelta a la moneda y se acuña la sentencia, "el Estado es el problema". Fuera de la ley del péndulo y más apegados a las décadas 1990 y 2000 podemos refundir ambas acuñaciones afirmando que tanto el mercado como el Estado son hoy un problema: ¿cuál y cómo debe ser el Estado que nos ayude a convivir con la "paz violenta" gestada por el mercado? Los testimonios de A. Schelesinger, F. Hinkelammert, Seattle, Bangkok... nos muestran que el mercado es una realidad plagada de incertidumbres, asimetría y agresividad. Deseo agregar un testimonio tan acústico como realista.

Edwart Luttwak, del Centro de Estudios Estratégicos e Internacionales de Washington, publica su última obra con el título de "Turbocapitalismo". Él es un defensor del capitalismo tradicional basado en la libre competencia, pero lo 
que está cambiando son las normas y características del mercado de libre competencia. El capitalismo se ha transformado en "turbocapitalismo". En el capítulo segundo se pregunta: ¿qué es turbocapitalismo?. "Sus partidarios no utilizan este término, simplemente lo llaman libre mercado, pero por ese par de palabras entienden mucho más que la libertad para comprar y vender. Lo que ensalzan, predican y exigen es un sistema de empresa privada liberado de las regulaciones gubernamentales, sin un control por parte de sindicatos efectivos, sin la traba de escrúpulos sentimentales sobre el destino de los trabajadores o de las comunidades, sin la limitación de barreras aduaneras o restricciones a la inversión y con la mínima imposición fiscal posible. Lo que reclaman con insistencia es la privatización de todos los negocios en manos del Estado y la conversión de las instituciones públicas - desde las universidades y jardines botánicos hasta los centros penitenciarios, desde las bibliotecas y escuelas públicas hasta los geriátricos- en empresas privadas dirigidas al lucro. Lo que prometen es una economía más dinámica que generará más riqueza. En cambio, de lo que no hablan es de la distribución de esa riqueza, ya sea de viejo o nuevo cuño.

Lo llaman el libre mercado, pero yo lo denomino capitalismo turboalimentado o, por brevedad del término, turbocapitalismo, pues se diferencia mucho del capitalismo estrictamente controlado, que surgió en 1945 y se mantuvo hasta la década de los ochenta, de aquel que trajo la sensacional novedad de la opulencia a los habitantes de Estados Unidos, Europa occidental, de Japón y de todos los paises que siguieron este camino... Según los entusiastas del turbocapitalismo actual, esos tres modelos se redujeron a una interferencia perniciosa del Estado destinado a causar ineficiencias grotescas y un crecimiento económico lento. No obstante, para su completo desconcierto, el crecimiento económico bajo esos tres modelos fue mucho más rápido en los años cincuenta, sesenta y setenta de lo que es hoy"...

..."Que el capitalismo sin la obstrucción de la propiedad estatal, regulaciones gubernamentales, cárteles, monopolios, sindicatos efectivos, inhibiciones culturales u obligaciones familiares es con mucho el sistema más productivo jamás inventado en el planeta es una verdad muy vieja que ahora sólo discuten unos pocos académicos occidentales. Que el capitalismo crece como lo hace porque su implacable competencia elimina las estructuras y los métodos ineficientes y, por tanto, en lugar de eso permite el desarrollo de estructuras y métodos más eficientes es una sencilla idea económica que todo el mundo entiende. Y finalmente, que un cambio estructural veloz puede infligir más trastorno a los trabajadores, a las empresas, a sectores industriales enteros y a sus localidades de los que los individuos pueden tolerar o más del que puede aguantar el tejido conjuntivo de amigos, familiares, clanes, agrupamientos electivos, vecinos, aldeas, pueblos, ciudades o, incluso, de toda la nación, también es una vieja verdad"... ("Turbocapitalismo: ¿Quiénes ganan y quiénes pierden en la globalización?" Ed. Crítica. Barcelona, 2000; pp. 49-50) 
Si en Davos-2000 se habló de la exuberante economía de los EEUU y de la racionalidad de su bolsa de valores, también se lanzaron dos bengalas de advertencia. L. Summers, Secretario del Tesoro, reconoció las desigualdades aún presentes en la sociedad estadounidense en lo referente a las tasas de desempleo y la esperanza de vida entre regiones. Sobre todo "mostró su preocupación por el bajo ahorro de los hogares estadounidenses, algo que los expertos reunidos aquí llaman elevado endeudamiento, y que, en caso de ralentización económica, colocaría en dificultades a muchas familias", Por su parte Stanley Fischer, del FMI, "aseguró estar inquieto por la desbocada marcha de la economía estadounidense, que podría verse abocada a una caída drástica en el caso de que los actuales ritmos de crecimiento no puedan ser controlados". (ECA 2000; pp.122-124) Sin embargo, las desigualdades de ingresos y riqueza son mayores que las indicadas por el Secretario del Tesoro, y el problema del endeudamiento se explica por la marcha alocada de la economía, que resalta $\mathrm{S}$. Fischer.

Luttwak E. nos presenta dos cuadros sobre lo que podríamos llamar la curva de Lorenz norteamericana. El primer cuadro representa "la distribución del ingreso familiar agregado en Estados Unidos (antes de las transferencias gubernamentales), 1995(\%)

- $120 \%$ de las familias con menos ingresos .................................. $0,9 \%$

- segundo 20 por 100 de familias .................................................. 7,2\%

- Tercer 20 por 100 de las familias ............................................. 14,7\%

- Cuarto 20 por 100 de las familias .............................................. 24,2\%

— 20 por 100 de familias con más ingresos ................................ 52,9\%

Este cuadro muestra la abierta desigualdad que, por sí mismo, genera el mercado.

Dado que el Estado cobra impuestos y realiza algunas formas de distribución social, la distribución del ingreso familiar reduce parcialmente dicha desigualdad.

- 20 por 100 de las familias con menos ingresos ........................... $5,2 \%$

- Segundo 20 por 100 de familias ................................................ 11,0\%

- Tercer 20 por 100 de familias ................................................ 16,3\%

- Cuarto 20 por 100 de familias ................................................... 23,4\%

- 20 por 100 de las familias con más ingresos .............................. 44,1\%

Para visualizar la concentración del ingreso-riqueza en la cúspide de la pirámide Lutwak presenta la concentración de la Renta Nacional en el 5\% de familias con mayores ingresos. De acuerdo a la oficina de Censos (Inequality of distribution) ese $5 \%$ de familias retenía el $16,8 \%$ de la Renta en 1977 y su 
porción ascendía al 21,2\%en 1994. (lbidem; pp. 120-124). Este fenómeno de la concentración, bastante afín a nuestra curva de Lorenz, que ya había sido comentado por $\mathbf{A}$. Schelesinger, esconde otro fenómeno alarmante: el endeudamiento de las empresas y familias, que sostiene lo que $\mathrm{S}$. Fischer llama la alocada marcha de la economía.

La Prensa Gráfica traslada un artículo de The Wall Street Journal Americas, firmado por G. Zuckerman: "Con préstamos fáciles, E.U.A. se vuelve un país de deudores". Las cifras son alarmantes. "Las empresas estadounidenses no financieras han acumulado la cifra récord de US $\$ 4,5$ billones en deuda, un incremento del $67 \%$ en los últimos cinco años, según la Reserva Federal; y el endeudamiento de los hogares ha aumentado en al menos un $60 \%$ hasta los US $\$ 6,5$ billones"... "El incremento de la deuda no es necesariamente malo, ya que ha ayudado a que las compañías se expandan y ha impulsado el consumo, alimentado el crecimiento económico. Pero las campanas de alerta están comenzando a sonar, y no sólo porque el crédito haya alcanzado niveles récord. A ello se suma el hecho de que las compañías y los consumidores menos capacitados para enfrentarse a un préstamo han sido los que más han aumentado sus deudas, y si la economía sufre un revés, muchos de estos créditos podrían quedar impagados"... (La Prensa Gráfica, 6 julio 2000)

Con fecha 24 de abril El País publica dos artículos sobre el creciente endeudamiento de personas y familias para adquisición de títulos en bolsa de valores, enrolándose en la turboespeculación que puede hacer ricos en pocos días. "El dinero de Wall Street se rinde ante un grupo de jóvenes ricos gracias a Internet". El otro artículo, titulado "La peor pesadilla del especulador aficionado", describe con más datos la dinámica del endeudamiento. "La creciente tendencia del pequeño inversor de EEUU a endeudarse para comprar acciones y los vaivenes cada vez mayores en las cotizaciones amenazan con desestabilizar los mercados... El mecanismo es sencillo. El inversor solicita un crédito a su intermediario bursátil para comprar acciones... El año pasado, el volumen de estos créditos se disparó un $62 \%$ hasta un récord de 230.000 millones de dólares." "Aquí se pide prestado para comprar acciones" dice el vicepresidente de la Bolsa de Nueva York. "Sé que en Europa no es costumbre, pero en Estados Unidos está muy extendido". Cuando el mercado se da la vuelta, este mecanismo se convierte en una trampa mortal para el inversor. Si el valor de las acciones compradas a crédito cae por debajo de un determinado nivel, los intermediarios bursátiles levantan el teléfono a sus clientes: o se aporta más dinero o se venden las acciones... Estas llamadas de alerta ejercen además un efecto perverso en el mercado. Porque se producen evidentemente cuando las acciones caen, no cuando suben. La solución sería endurecer las normas para la concesión de créditos, pero los dirigentes de las bolsas temen que si se aplican normas más restrictivas "podríamos desatar un pánico vendedor"... 
Estos breves fragmentos, cuyos detalles pueden consultarse en la bibliografía citada, muestran los claroscuros de la "nueva economía", donde planea la especulación, sobre todo, en tomo a los títulos de las nuevas empresas de servicios que, si no son las creadoras de empleo, ofrecen rápidos beneficios (Turbocapitalismo; pp. 110-114) y donde se van gestando las mayores desigualdades de ingresos. Ante esta situación se plantea la alternativa del laissez-faire o de gobemar la globalización por parte del Estado. La "nueva economía", con sus consecuencias, no puede exportarse como el modelo de la economía mundial. Por esta razón reconocidos autores reclaman la presencia del Estado, corrigiendo los crecientes desequilibrios sociales. Este es uno de los temas del actual debate.

El financista y filántropo George Soros, exponiendo cinco deficiencias en el capitalismo global, integra la ausencia del Estado como una de estas deficiencias. “ ¿A quién corresponde evitar una concentración de poder indebida y salvaguardar la estabilidad? Esto me lleva al papel del Estado. Desde el final de la II Guerra Mundial el Estado ha desempeñado un papel creciente en el mantenimiento de la estabilidad económica, y se ha esforzado por garantizar la igualdad de oportunidades y proporcionar una red de seguridad social, especialmente en las naciones altamente industrializadas de Europa y América del Norte. Pero la capacidad del Estado para preocuparse del bienestar de sus ciudadanos se ha visto gravemente afectada por la globalización... Ello conduce a un aumento del desempleo, que es lo que ha sucedido en Europa continental. No estoy defendiendo los anticuados sistemas europeos de seguridad social, necesitan urgente reforma, pero me preocupa la reducción de las prestaciones sociales tanto en Europa como en América...

Los gobiernos de Tatcher y Reagan comenzaron a reducir el papel del Estado en la economía. Su consecuencia fue que los impuestos sobre el capital descendieron significativamente, mientras que los impuestos sobre el trabajo han seguido.creciendo. Como asegura el economista internacional Dani Rodrik, la globalización aumentó las demandas al Estado de que proporcione una seguridad social al mismo tiempo que reduce su capacidad para hacerlo. Esto lleva en sí el germen de conflictos sociales. Si los servicios sociales se recortan en exceso, al tiempo que aumenta la inestabilidad, la insatisfacción popular podría desatar oleadas de proteccionismo, especialmente si (o cuando) la expansión actual va seguida de una recesión de cierta gravedad. Esto podría conducir a un colapso como el de los años treinta. Al declinar la influencia del Estado hay mayor necesidad de cooperación internacional. Pero esa cooperación es contraria a las ideas del laissez-faire, por un lado, y de nacionalismo o fundamentalismo, por el otro". ("Hacia una sociedad abierta global". El País, 22 diciembre 1997)

A. Schelesinger también lamenta la destrucción del Estado y de la misma identidad nacional, anunciando las previsibles consecuencias. "Un candidato - no previsto - para la destrucción capitalista es el Estado nacional, tradicional asien- 
to de la democracia. El ordenador convierte el mercado sin trabas en un monstruo global irresistible, que atraviesa las fronteras, debilita los poderes nacionales de implementación de impuestos y regulaciones, impide la gestión nacional de las tasas de interés e intercambio, amplia las disparidades de riqueza lo mismo dentro de las naciones que entre ellas, derrumba las normas laborales, degrada el medio ambiente, niega a las naciones el poder de dar forma a su propio destino económico, sin dar cuenta a nadie y crea una economía mundial sin una política mundial. El ciberespacio está más allá del control nacional. No existen autoridades que proporcionen control internacional. ¿Dónde está ahora la democracia?".

Schelesinger prevé dos tipos de reacciones; por una parte los movimientos centrífugos que ansían una política de identidad. "Cuanto más rápidamente se integra el mundo, más personas se refugiarán en sus enclaves religiosos, étnicos o tribales. La integración y la desintegración se alimentan mútuamente". Paradoja globalizante: pocas veces el mundo ha estado tan unido por el mercado y, al mismo tiempo, tan fraccionado por el mismo mercado. Al movimiento centrífugo se une la protesta y el rechazo, porque este capitalismo "provoca el resentimiento social, resucita la guerra de clases y da nueva vida al marxismo... La democracia del siglo-XXI debe entendérselas con las presiones de la raza, la tecnología y el capitalismo, y hacer frente a las frustraciones y ansias espirituales generadas en el vasto anonimato de la sociedad global". " ¿Tiene futuro la democracia?". Política Exterior, № 60, 1997)

En el foro de Davos 1999 se había planteado el problema para los Estados: cómo integrar "democracia, gobernabilidad y desigualdad". El mercado global, generador de desigualdades crecientes, desarticula la democracia y desquicia la gobernabilidad. (ECA 1999; pp. 469-470) Alain Tourraine ya había advertido sobre las consecuencias de este dilema: "Cuanto más compleja es una economía, más difícil es lograr un crecimiento duradero, y la importancia de esta idea proviene de que muestra hasta qué punto los equilibrios internos de una sociedad se han convertido en condiciones necesarias para el crecimiento de una economía. Estos equilibrios sociales no se mantienen espontáneamente; al contrario, la economía de mercado crea desequilibrios y fuerzas de acumulación y de exclusión que amenazan a los equilibrios básicos de la sociedad. Estos, para ser restablecidos, requieren la intervención del Estado y de otros agentes propiamente políticos y sociales...

Nadie puede desear que se ensanche el abismo que separa ya el mundo económico de los mundos político o cultural. Por tanto, es necesario hacer lo posible para que se forme una voluntad colectiva de poner fin al desarrollo sin freno del capitalismo, es decir, de la economía de mercado, mientras rechace todo control político y social de sus actividades. Hay que restablecer el control de los medios económicos para las finalidades políticas y sociales... La tormenta 
se escucha casi por todas partes, excepto en Estados Unidos, y en todas partes, incluido Estados Unidos, aumenta el temor de una crisis económica grave, que incrementará la pobreza, la desigualdad y la exclusión de una manera insoportable. El largo silencio de la época neoliberal debe terminar y el debate público sobre los fines y los medios de la economía debe revivir. No perdamos más tiempo". (Realidad, 1998. № 61; pp.24-25)

Estas palabras de A. Tourraine han venido acompañadas de dos hechos históricos. Hoy día la mayoría de gobiernos de Europa occidental son, o se dicen, de centro-izquierda, sociales o socialdemócratas, integrados casi todos a la Internacional Socialista, rezumando nostalgias por el Estado social de bienestar. Otro signo de nuestros tiempos es que hemos entrado en la era de los manifestantes y de las manifestaciones, sobre todo en el hemisferio Norte. También crece el número de ONG's del Sur que se integran a las manifestaciones ya anunciadas para próximas cumbres mundiales del FMI-Banco Mundial o de las Naciones Unidas...

Más cercanos a nuestra realidad latinoamericana, el Informe 2000 del BID, "Desarrollo más allá de la economía", señala en su prefacio lo siguiente: "Pero lo más crítico del patrón de desarrollo económico latinoamericano se encuentra en la forma en que está distribuido el ingreso... En América Latina se encuentran algunos de los países con las peores distribuciones de ingresos del mundo. Pero incluso aquellos países con las mejores distribuciones de ingreso de la región presentan índices de concentración que superan el promedio mundial. Por consiguiente, la mala distribución del ingreso es un rasgo común a toda la región". (p.VI) El expresidente uruguayo J. M. Sanguinetti, ponente en los cursos de la Universidad Internacional Menéndez Pelayo en Santander, España, dijo que para hacer frente a la globalización el Estado debe defender "la identidad cultural de cada nación y compensar las situaciones de desigualdad que produce ese aluvión economicista. Con el desarreglo económico se pierden las opciones, el Estado queda inerme y al final termina muriendo en la mesa de los acreedores. En América Latina hay que hacer un esfuerzo enorme en este sentido. Ha crecido y se ha modernizado, pero no ha mejorado su distribución de ingresos. El mayor problema para la adaptación a la globalización sería el desarrollo de una conciencia clara de cómo han de manejar esta situación los Estados, evitando "transformar la globalización en una especie de monstruo abstracto que nos exculpa de nuestras responsabilidades". Los Estados deben empezar ya a desarrollar con persistencia políticas redistributivas de riqueza porque las respuestas no son rápidas, requieren normalmente una generación. Lo que más nos ayuda hoy a defender nuestras políticas de desarrollo es la inversión, la cooperación técnica y el intercambio comercial estable".("Sanguinetti: El Estado debe compensar las desigualdades causadas por la globalización". El País. 21 julio 2000)

Esto significa que a nivel de Gobiernos y de representantes de la sociedad civil crece un proceso de crítica del libre juego del mercado y en consecuencia 
la necesidad de gobernar la globalización. Volvemos a preguntarnos cuál es el papel del Estado en este escenario convulsionado. Ojalá no sea erróneo decir que en El Salvador nos hallamos en una fase de inconformidad, de búsqueda y de transición ante el sentimiento de que no hay gobierno, ni un plan nacional de gobiemo. A fuerza de repetir que el Estado es el problema hemos creado otro problema mayor: ya no sabemos cuál es la función del gobierno. Prueba de ello es el creciente abstencionismo en los procesos electorales: gobierno ¿para qué?. Tampoco estamos satisfechos con el regulador del mercado, que ha convertido la década de los noventa en una "década truncada". Esta no es una afirmación visceral. Baste leer en el libro de Roberto Rivera Campos las páginas 2-4, que resumen los objetivos del Programa-ARENA 1989... y evaluar los resultados fallidos, comentados en las páginas finales 241-247. El último párrafo muestra que han fallado nuestro mercado y nuestro Estado: "Fortalecimiento del mercado, estado pequeño, eficiente y fuerte, estado de derecho, seguridad ciudadana, educación y salud, parecen ser los cinco pilares mínimos que un país pequeño puede necesitar para llevar progreso a sus ciudadanos. Fortalecer o construir estos cinco pilares constituye el gran desafío de los salvadoreños de cara al próximo siglo". (p.247)

Leyendo este párrafo a los seis u ocho meses de su publicación cada palabra tiene una traducción concreta. Fortalecimiento del mercado no es un panegírico al libre mercado, sino reconocimiento de nuestra deficiente capacidad competitiva. Al cerrarse el primer semestre 2000 Luis Membreno titula su columna de El Financiero, "Segundo trimestre peor". De acuerdo al autor podemos hablar de recesión económica, porque las expectativas del tercer trimestre son oscuras, y más bien hemos entrado en una fase de estanflación económica, estancamiento con alza de precios. (La Prensa Gráfica, 18 de julio 2000; p. 4b) Proceso, No 910, detalla este estadio de ralentización subrayando el creciente déficit de la balanza comercial e incluso de la cuenta de capital. El hecho de que en el Presupuesto-2001 se programe un incremento de las carteras de educación, salud y seguridad nacional, que esperamos se realicen, es un reconocimiento implícito de la necesidad de fortalecer las dos primeras inversiones sociales, y de enfrentar el incontrolable flagelo de la inseguridad ciudadana, con sus ramificaciones en instituciones gubernamentales, así como el tortugismo en los procesos de seguimiento e investigación de conspicuos delitos. Con ello el Estado de Derecho sigue siendo un punto en el horizonte nacional. Sentimos que el gobierno y la misma sociedad se ven arrollados por esta avalancha de sucesos.

En este escenario algo desconcertante, el actual gobierno no prestó atención a valiosos aportes que le ofrecía la sociedad; documentos nacidos de la consulta popular y de autorizados profesionales académicos. Me refiero a los análisis de Bases para un plan de nación; Temas claves para un plan de nación: consulta especializada; Estado de la nación en desarrollo humano; Crecimiento estéril o desarrollo; Crecimiento con participación... Se trata de dos aportes; el primero, 
la voluntad de participar en la solución de estos desafíos nacionales. Segundo, los propios análisis académicos en cada una de las mesas o problemas estructurales e interrelacionados que se entrecruzan en todos estos documentos. Personalmente, trate de presentar un análisis cruzado del ordenamiento de estos temas y problemas, así como de los puntos que quedaban en litigio, de acuerdo a las diversas ideas o ideologías. Había un consenso generalizado en la necesidad de diseñar un "Plan de Nación". que coordinara los mayores desafíos nacionales y, si fuera necesario, la reestructuración de una Secretaría o Ministerio de Planeación y Coordinación del Desarrollo. El Estado debía tomar las riendas de la dirección económica y abrirse al diálogo con la sociedad, deseosa de aportar y participar. Se trataba de una planeación concertada y democrática. ("Estado y plan de nación privado". Realidad, 1999, № 70)

Luego del primer año de gobierno tenemos que lamentar su distanciamiento de una sociedad abierta a colaborar, así como la ausencia de una "plan de nación". El regulador de la economía que se enuncia en el Programa de Gobierno: La Nueva Alianza" no ha sido muy eficiente: "El Estado tiene un rol subsidiario: es decir, todo lo que puedan realizar los privados o el mercado debe trasladarse a éstos". (p.5) El señor Presidente tardó un año en reconocer que había recibido una mala herencia económica, de lo cual todos somos conscientes. Lo que más aflige es que algunas instituciones o miembros del gobierno, entre otros el BCR, no acaban de reconocer esté debilitamiento económico y, en consecuencia, que no se mencione otro remedio que la caja de convertibilidad o la dolarización. Los problemas económicos son muy reales y demasiado graves como para corregirlos con un simple cambio del signo monetario. La economía real necesita una planeación real. Sobre todo que el Gobiemo debe ir más allá de los solos problemas económicos para conjugarlos con el reino de los derechos humanos, un desafío que vuelve a actualizarse con el huracán de la globalización. Nos quedamos a la espera de los resultados que puedan derivarse, en este sentido, del diálogo ANEP-Gobierno, luego de la presentación del programa ENADE2000.

\section{El derecho a tener derechos.}

En 1998 se celebró el $50^{\circ}$ aniversario de la "Declaración Universal de los Derechos Humanos" y en 1999 Juan Pablo-II dedicó su mensaje de la paz al "respeto de los derecho humanos", $1^{\circ}$ enero 1999. (Realidad, 1999; pp.69-93) Siendo estos derechos humanos tan prolijos en sus ramificaciones, los Estados son invitados a deliberar y ratificar numerosos tratados o protocolos que, directa $o$ indirectamente, se relacionan con estos derechos. Si bien los gobiernos, sobre todo las grandes potencias, olvidan ratificar o incumplen lo que firmaron, crece la conciencia del "derecho a tener derechos" y de exigir a los Estados su cumplimiento. Poniendo algún ejemplo, la Organización Internacional del Trabajo (OIT) protege los derechos laborales, que ciertos gobiernos aplican a terceros países y 
se olvidan de aplicarlos a sus propias empresas. La Organización Mundial del Comercio (OMC) norma las relaciones comerciales, pero en Seattle estalló la protesta porque los países en desarrollo no son norma, sino normados. El Tribunal Penal Internacional, Roma 1998, ha sido firmado por muchos países, pero hasta el presente muy pocos han armonizado sus constituciones con las cláusulas del tratado. El Protocolo de Kyoto, 1998, sobre el efecto-invernadero, tuvo tanto beneplácito como descuido de parte de los grandes contaminadores del medio ambiente. El Tratado de Minas-Antipersonas y el Tratado de Proliferación Nuclear, 1999, simplemente no fue firmado por las grandes potencias nucleares; ahora EEUU intenta ganarse socios para construir un paraguas antimisil que los proteja de los "nuevos terroristas", Corea, Irán, Irak... El mismo incumplimiento hace madurar la conciencia de derechos no considerados antes como derechos. Es lógico que el tema de los derechos humanos se debata en tantos encuentros y seminarios, comprometiendo a los Estados nacionales desde una óptica concreta.

"Globalización y derechos humanos"; "La globalización obliga a renovar los derechos humanos, según políticos, académicos y ONG". Son dos títulos de la conferencia organizada por la UNESCO en Santiago de Compostela, España, primero de julio 2000 . Se trata de ir creando un código ético para la era de la globalización a través de un debate abierto con ponentes internacionales. Resulta obligado sintetizar algunas de las intervenciones. Danielle Mitterand, viuda del ex-presidente francés, abre el fuego con un mensaje radical: "El final de la guerra fría ha supuesto el triunfo de un pensamiento único, de una doctrina dogmática mundial, que impone una forma de vida y una forma de muerte". Se dispara el debate sobre una jerarquización de los derechos humanos, aunque el objetivo es dejar libre expresión a los ponentes. "Sin derechos políticos y civiles -y en su centro el derecho a la vida - no puede haber derechos sociales, pues de poco valdrían los primeros si la pobreza y la miseria impiden ejercerlos". El catedrático de derecho constitucional, F. Rubio Llorente afirma: "Hay unos derechos humanos más indispensables que otros. El derecho a la vida es más importante que el derecho al medio ambiente". El comisionado europeo para derechos humanos, A. Gil Robles dijo: "Hace unos meses estuve en Chechenia y nadie me hablaba del medio ambiente, sino de salvar la vida, de que no violasen a sus hijas y de que no torturaran a sus hijos".

Para el PNUD "la pobreza es un tema tanto de derechos humanos como la tortura, cuando, por ejemplo, mueren 30.000 niños al día en el mundo de causas que se pueden prevenir". El Mahamma Gandhi ya había dicho que "la pobreza es la mayor violencia". "La erradicación de la pobreza se está convirtiendo en un reto central para los derechos humanos especialmente cuando crecen las diferencias entre los más ricos y los menos afortunados". El PNUD propone como arma pacífica el uso de las estadísticas en materia de respeto a los derechos humanos, "como instrumento para crear una cultura que obligue a rendir cuentas a los dirigentes". La investigadora mexicana Gloria Rodríguez se pronunció a 
favor de la universalidad de los derechos humanos - pese a las diversidades lingüísticas y culturales - argumentando que "son los indígenas, los que fueron excluidos en la creación de los Estados nacionales, quienes enarbolan ahora esa bandera". La idea de "un hombre, un voto, es lo que acabó con el apartheid en Sudáfrica". "Muchas minorías étnicas ven restringido el acceso a los servicios públicos, al agua, la sanidad, de que gozan las mayorías que controlan algunos Estados".

Dentro de esta polifonía de los derechos humanos aparecen otras interesantes aplicaciones. El profesor uruguayo $\mathrm{H}$. Gros Espiel destaca la necesidad de conciliar la libertad de investigación científica con los límites éticos. Puso un ejemplo: La aceptación de la clonación humana con fines reproductivos violaría el principio de la individualidad de los seres humanos, nuestro carácter de ser únicos"... No podía faltar el tema del "derecho de injerencia", luego de la declaración de la "guerra-humanitaria" de Serbia-Kosovo. En el seminario se dijo que "el derecho de injerencia" suena como "palabra maldita" en América Latina, y las razones son claras. Los representantes del Tercer Mundo temen que estas intervenciones armadas se conviertan en un nuevo estadio de un colonialismo occidental. Este derecho se legitimaría bajo las siguientes condiciones: "Que sea a favor de los agredidos; que sea la ONU quien decida las intervenciones con misión humanitaria; que se reconozca el derecho a la autodeterminación de las minorías y que lo pueda ejercer también el débil frente al fuerte".

El polaco Adam Michnick, del movimiento Solidaridad, recordó que "la declaración de los derechos humanos fue el programa de la oposición polaca durante la era soviética y la diversidad suele ser un pretexto de las dictaduras. Los derechos humanos no son una receta para todos los dolores de la humanidad. Son sólo una propuesta para evitar la tiranía política, y su consecución es un camino que se construye paso a paso". Su colega Bronislav Geremek ("Por un club mundial de Estados democráticos") actualiza el grito de Solidaridad en los años 80": "no hay pan sin libertad", y agrega "la libertad sin pan es una farsa".

La conferencia se clausuró sin conclusiones propiamente dichas para no traicionar el carácter abierto de los debates. Tuvo mayoritaria adhesión la idea del profesor tunecino Yadh Ben Achour para "la creación de instrumentos legales de ámbito planetario que persigan la vulneración de los derechos humanos. Los países democráticos no deben conformarse con la instauración del Tribunal Penal Internacional, ya que éste se limitará a enjuiciar delitos de extrema gravedad como los genocidios". La propuesta fue apoyada y complementada por el exministro colombiano A. Ramirez Ocampo, quien propone "la creación de un Tribunal Constitucional Internacional que perseguiría actuaciones de Gobiernos autoritarios como los fraudes electorales y los ataques a las libertades"...

Al redactar estas páginas nos hallamos confrontados con la "cultura", en su sentido etimológico, del secuestro, del espionaje telefónico, de las avionetas- 
narcotráfico, de la pérdida de credibilidad en la policía nacional civil, de las investigaciones "con preaviso", de la inseguridad generalizada que, lejos de atraer la inversión extranjera, puede generar la escapada de capitales nacionales. Hemos llegado a una situación en que no se respeta el primer derecho fundamental, la vida física y moral. Se podrá decir que, lamentablemente, este es un problema mundial y que la "nueva economía" norteamericana cohabita con dos millones de ciudadanos "entre las rejas". No vamos a culpar de todo a la globalización, pero sí hay problemas que engorda la globalización y terminan en crisis de gobernabilidad.

Una semana después del seminario de Santiago de Compostela Joaquín Estefanía redacta un breve comentario: "Organismos contra la pobreza". (El País, 9 de julio 2000)

Estefanía afirma que varias de las principales organizaciones internacionales "han dado un cierto giro, al menos teórico, en sus preocupaciones y comienzan a hablar de la pobreza. No es para menos: el incremento de la pobreza y de las desigualdades en el mundo, sobre todo en los últimos veinte años (los de la hegemonía de la revolución conservadora), es tan espectacular que amenaza con deslegitimar todo el proceso de globalización y hasta el paradigma de la "nueva economía". Estefanía repite estadísticas similares a las expuestas por $\mathbf{J}$. Wolfensohn en octubre de 1998, (ECA, 1998; p. 1004) y nos envía al reciente informe de la ONU, OCDE, FMI y BM: "un mundo mejor para todos". Estas instituciones afirman que "la pobreza, en todas sus formas, es el mayor desafío de la comunidad internacional" y urgen a los países ricos a reducir la pobreza a la mitad de aquí al año 2015, no sólo porque el mundo será así mejor, sino porque "será más seguro". Es decir, añade Estefanía, se trata de una respuesta egoísta, pero menos da una piedra. Para reducir la pobreza, dice el informe "no basta con el crecimiento económico"; hay que invertir en educación, sanidad.

Estas instituciones $i$ dan muestras de verdadera contrición o de simple atrición ante las consecuencias que ellas retroalimentaron?. "La pobreza y las desigualdades no son un fenómeno natural, sino el fruto de políticas económicas equivocadas, o corruptas o defensoras de los intereses de los más poderosos. Esas políticas son instrumentadas por los gobiernos nacionales, pero en muchos casos han sido recomendadas por las instituciones que ahora denuncian esos abusos del sistema". J. Stiglitz, marginado del Banco Mundial y que "quizá ya no obtenga el Nobel de Economía", atacó al FMI: "Desde el final de la guerra fría la gente encargada de difundir el evangelio del mercado por los rincones remotos del planeta ha adquirido un poder tremendo. Estos economistas, burócratas y funcionarios actúan en nombre de los Estados Unidos y de los demás países industrializados, pero hablan un idioma que muy pocos ciudadanos corrientes entienden y que pocos políticos se molestan en traducir". Según Stiglitz, el FMI apoya a las instituciones democráticas de los países a los que ayuda; en 
la práctica, socava el proceso democrático al imponer su política". (El País, 9 de julio de 2000)

En entrevista que el diario El País hiciera a M. Camdessus en su residencia de París, el ex-director del FMI mezcla un "claroscuro" de respuestas. "Aunque es verdad que, si hay un peligro de hacer estallar este sistema, es la pobreza y las diferencias enormes entre pobres y ricos que ha generado. Brasil es un claro ejemplo de cómo la injusta distribución de la tierra y los ingresos se ha convertido en la primera causa de sus problemas económicos"... "Nosotros nunca dijimos que había que cortar en salud, educación, sino con menos gasto hacer más. Lo que hemos atacado no es el gasto social, sino el gasto improductivo"... "La historia humana es trágica por naturaleza y, cuando se cambia para mejorar las cosas, siempre hay costos intermedios. Sabíamos perfectamente que desprenderse de las empresas públicas y la flexibilización laboral iban a dejar gente en la calle. Pero son fenómenos transitorios en una estrategia que me parece ha servido al desarrollo humano. Por doloroso que sea, era necesario pasar por todo esto para hacer empresas más productivas"..."Es un escándalo que en tiempos de prosperidad como éste, cuando el conflicto Este-Oeste ya no existe y ha permitido reducir gastos militares, la ayuda al desarrollo, en lugar de crecer, haya bajado"..."Aunque hemos hecho todo lo que está en nuestras manos para combatir este nuevo capitalismo basado en la corrupción, el nepotismo y el amiguismo, poco podíamos hacer... Se ha empezado a hablar de este capitalismo del amiguismo y de las oligarquías ligadas al poder a propósito de Rusia, pero donde ha aparecido ya el fenómeno en su forma más sangrante había sido en Asia. En Tailandia, Corea y particularmente Indonesia... Señor Yeltsin, usted tiene los mismos problemas que esos países asiáticos; si usted no combate la corrupción y el nepotismo, su sistema se va a derrumbar"..."Se ha visto que el mercado sólo, sin regulación eficiente, no funciona bien y puede crear situaciones sociales y de poder destructoras para la democracia y para el mismo mercado. Pero es el sistema más eficaz, cuyos vicios se trata ahora de corregir"... ( Pepa Roma: "La pobreza puede hacer estallar este sistema". El País, 24 abril del 2000)

Algunos signos de arrepentimiento aparecen en el discurso de J. Wolfensohn ("La otra crisis") de octubre 1998. "Hemos comprobado que cuando pedimos a los gobiernos que adopten medidas rigurosas para organizar suss economías, podemos generar enormes tensiones. Quien sufre es la gente, no los gobiernos... Debemos aprender a entablar un debate en el que las matemáticas no valgan más que las razones humanitarias, en que la necesidad de cambios, con frecuencia drásticos, sea compatible con la protección de los intereses de los pobres. Sólo entonces llegaremos a soluciones sostenibles... Los problemas son demasiado graves, y sus consecuencias demasiado importantes, para conformarnos con las respuestas del pasado o con las modas e ideologías del momento"...(Ibídem, pp. 1004-1005) 
Es necesario que los "ideólogos" de ARENA reflexionen sus principios económicos. En mayo de 1989 fundamentaron su modelo de economía de mercado - para una sociedad libre - en tres parámetros: la propiedad privada es condición necesaria para la eficiencia de la producción; el mercado es el mejor asignador de recursos y la competencia garantiza el funcionamiento del mercado. En consecuencia, el Estado desempeña un papel subsidiario. Once años más tarde el Informe del BID 2000, cuyo título es "Desarrollo más allá de la economía", caracteriza a Latinoamérica con estos críticos problemas: las escasas oportunidades laborales, la carencia de educación, la pobreza, la corrupción y la delincuencia. "Pero lo más crítico del patrón de desarrollo económico latinoamericano se encuentra en la forma como está distribuido el ingreso... Por consiguiente, la mala distribución es un rasgo común a toda la región. (Prefacio; v-vi) Lo menos que podemos pedir es que no se quieran ocultar estas realidades.

\section{Capitalismo frente a democracia.}

George Soros vuelve a la carga. Dos años después de su artículo "Hacia una sociedad abierta global", nos dice que, "aunque el capitalismo triunfa, no podemos hablar del triunfo de la democracia". El presente artículo sirve a recopilar algunos de los acápites aquí comentados. "La conexión entre capitalismo y democracia dista mucho de ser automática...

El capitalismo crea riqueza, pero no se puede depender de él para garantizar la libertad, la democracia y el Estado de derecho. Las empresas están motivadas por el beneficio, no tienen por objetivo salvaguardar los principios universales... Los participantes en el mercado compiten para ganar, y si pudieran eliminarían a la competencia. Por consiguiente, la libertad, la democracia y el Estado de derecho no pueden quedar al cuidado de las fuerzas del mercado; necesitamos garantías institucionales. Tradicionalmente, la protección del interés común era tarea del Estado nacional. Pero los poderes estatales se fueron reduciendo con la expansión progresiva de los mercados mundiales de capital... Pero la mundialización tiene sus desventajas: los mercados financieros son inestables; la libre competencia crea y refuerza las desigualdades en el ámbito nacional e internacional; los intereses colectivos, desde el mantenimiento de la paz hasta los derechos humanos o la protección del medio ambiente, reciben poca atención...

... En el mundo de hoy, la mayoría de conflictos no se producen entre Estados, sino dentro de los Estados... Los países democráticos no pueden tolerar la violación a gran escala de los derechos humanos, y pueden verse arrastrados a entrar en los conflictos locales... Soy partidario de un esfuerzo concertado por parte de las democracias desarrolladas para fomentar el desarrollo de la democracia en las partes menos desarrolladas del mundo. No se puede separar la economía de la política. Amartya Sen, galardonado con el Premio Nobel, razona de forma convincente que el desarrollo se debería definir basándose en el grado 
de libertad, no en el producto nacional bruto. El sistema capitalista mundial ha producido un campo de juego muy desigual. Las diferencias entre ricos y pobres se agrandan. Debemos encontrar formas de contrarrestar esto, porque un sistema que no ofrece esperanza y oportunidad a sus perdedores puede verse trastornado por actos de desesperación...

... El credo fundamentalista del mercado actual no reconoce que los mercados financieros son inestables por naturaleza. Al imponer disciplina de mercado lo que hace, de hecho, es imponer inestabilidad. Los mercados financieros mundiales necesitan un banco central mundial, o cualquier otra institución financiera que equilibre los mercados financieros. Lo mismo puede decirse de la Organización Mundial del Comercio (OMC). Hay una necesidad que clama al cielo de normas, laborales y para proteger el medio ambiente. Pero los países pobres no se las pueden permitir. En lugar de medidas sancionadoras para imponer estas normas, se debería dar a los países pobres incentivos para que las cumplan, como, por ejemplo, reducir los aranceles"... (El País, 15 de julio 2000)

Al cerrar el presente artículo con estas palabras de George Soros me siento inclinado a cambiar el título inicial, de acuerdo a los principios inspiradores de la globalización: "Teoría general de la "MONEDA", del desinterés y del subempleo". Por ello, con tantos autores, hablamos de "gobernar la globalización" para aprovechar sus avances tecnológicos y corregir su "eclipse social". 